\title{
Inflammatory Cells and Cytokines in the Olfactory Bulb of a Rat Model of Neuroinflammation; Insights into Neurodegeneration?
}

\author{
Marie-Francoise Doursout, ${ }^{1}$ Michael S. Schurdell, ${ }^{2}$ Lauren M. Young, ${ }^{2,3}$ Uzondu Osuagwu, ${ }^{2}$ \\ Diana M. Hook, ${ }^{2}$ Brian J. Poindexter, ${ }^{2}$ Mya C. Schiess, ${ }^{3}$ Diane L. M. Bick, ${ }^{2}$ and Roger J. Bick ${ }^{2}$
}

This study examined inflammatory cell and cytokine production in brain tissue from a lipopolysaccharide (LPS)treated rat model that mimics many of the neuropathologic changes associated with neurodegenerative diseases We also monitored the appearance of a glial cell line-derived neurotrophic factor (GDNF) and circulating nitric oxide (NO) levels, as well as an immune system-associated cells in a selected area of the brain, the olfactory lobe. The studies were based on the hypothesis that LPS treatment stimulates temporal changes within the brain and that these responses include immune cell recruitment, increased tissue levels of immune modulating cytokines and NO, as well as greater glial cell activation resulting in increased production of GDNF. As previously reported by other investigators, our animal model of systemic LPS treatment leads to an increase in the concentrations of circulating cytokines, including TNF- $\alpha$, IL-I $\beta$, and IL-6, with a maximum response $6 \mathrm{~h}$ post LPS administration. Concomitant with cytokine elevations, circulating NO levels were elevated for several hours post LPS administration. The brain content of the GDNF was also elevated over a similar time frame. Lymphocytes, neutrophils, macrophages, plasma cells, and cytokines were all seen in various areas of LPS-treated brains, often around blood vessels associated with the meninges, with these localizations possibly indicating involvement of both the blood-brain and blood-cerebral spinal fluid barriers in these inflammatory episodes. Our results suggest an involvement of both the peripheral and the central nervous system immune components in response to inflammation and inflammatory episodes. This leads us to propose that inflammation initiates an immune response by activating both microglia and astrocytes and that the presence of continuing and increasing proinflammatory mechanisms results in a situation, where cellular protective mechanisms are overcome and the more susceptible cells enter into cell death pathways, initiating a train of events that is a major part of neurodegeneration.

\section{Introduction}

$\mathrm{T}^{\mathrm{s}}$ HERE HAVE BEEN NUMEROUS reports that neurodegenerative diseases are caused by inflammation (Hisanaga and others 2001; Hirsch and Hunot 2009; Reale and others 2009). The inflammatory stimulus could be either a single massive event, or a sequence of smaller, additive events, or possibly a combination of both. Eventually, these responses can overwhelm innate protective mechanisms, leading to the death of the most susceptible cells, the dopaminergic neurons (Levy and others 2009). Other investigators have proposed that both peripheral and intracranial immune cells are intimately involved in inflammation and subsequent neurodegeneration and neurodisruptions associated with neurodegenerative diseases, including Parkinson's Disease (PD) (Monahan and others 2008). Furthermore, it has also been proposed that an increase in apoptosis of specific lymphocytes contributes to the development of neurodegeneration (Calopa and others 2010). Reynolds and coworkers reported the neuroprotective effects of a specific, $\mathrm{CD} 4+\mathrm{CD} 25+$ regulatory $\mathrm{T}$ cell population (Reynolds and others 2007), and subsequent work suggested that circulating, cytokine producing, monocytes were intimately involved in neuroprotection and proinflammatory cytokine production in patients (Rentzos and others 2009).

Bacterial endotoxin or LPS has been well documented both in vitro and in vivo to initiate robust inflammatory responses. It has proved to be an effective initiator of dopaminergic cell death both in vitro and in vivo (Tufecki and others 2011). A single systemic LPS injection in mice also induces a progressive degeneration of dopaminergic neurons in the substantia nigra, and a loss of neurons in other areas of

Departments of ${ }^{1}$ Anesthesiology, ${ }^{2}$ Pathology, and ${ }^{3}$ Neurology and Surgery, University of Texas Medical School at Houston, Houston, Texas. 
the brain (Qin and others 2007; German and others 2011; Venkateshappa and others 2011). We have previously demonstrated that cultured glial cells synthesize PD-associated proteins tau, alpha-synuclein, and ubiquitin, and that treatment of these cells with both cytokines and LPS resulted in protein aggregations, loss of cell adhesion, and necrotic cell death (Bick and others 2008; Dinh and others 2009; Schiess and others 2010). Similar protein aggregations were subsequently seen in brains of LPS-treated rats indicating that related mechanisms are potentially involved (unpublished data).

An inflammatory response has been linked to a neuroprotective protein, glial cell line-derived neurotrophic factor (GDNF) (Smith and Cass 2007), a protein that is synthesized by resident macrophages and microglia. In vitro, GDNF has proved to be an effective neuronal protective agent, such that, there have been suggestions of using bone marrowderived macrophages in the treatment of neurodegeneration (Biju and others 2010). As the pathobiology of neurodegeneration has become better understood, it has become apparent that cytokines have a pleiotrophic role; some are protective, while others may serve as markers for disease staging (Carlson and others 1999; Stoll and others 2000; Mogi and others 2007; Chiaretti and others 2008). Initial research on the role of cytokines implicated their involvement in signaling pathways and alterations in the integrity of the blood-brain barrier (BBB) (Munoz-Fernandez and Fresno, 1998), while changes in circulating cytokine levels have also been linked to neurodegeneration (Reale and others 2009; Rentzos and others 2009; Scalzo and others 2010). More recently, studies have shown that acute administration of LPS into the substantia nigra of rats leads to elevation of IL-1 $\beta$, TNF- $\alpha$, IL- 6 , and nitric oxide (NO) in this tissue (Herrera and others 2000; Arimoto and others 2007; Hernandez-Romero and others 2008) and increased expression of GDNF immunoreactivity in astrocytes (Iravani and others 2012).

Freely diffusible and reactive $\mathrm{NO}$ acts as a signaling molecule in many biological systems. It is produced by different isoforms of the enzyme NO synthase (NOS), including inducible NOS (iNOS) produced by activated macrophages / microglial cells. It is well described that NO has pleiotrophic effects, including vasodilatation of blood vessels and intercellular signaling within the nervous system. The role of $\mathrm{NO}$ in neuronal cell death induced by LPS is controversial, as some studies indicate no role for NO (Sachdeva and others 2011), while other evidence supports the hypothesis that LPS induces excessive production of NO, precipitating neurodegeneration (Dutta and others 2008; Long-Smith and others 2009).

Changes in olfaction are one of the early preclinical indicators of PD and often appears years before motor disturbance. Neuropathological studies indicate that the olfactory bulb is a primary region associated with the development of neurodegenerative pathologies (Doty 2011). We have consequently chosen to direct our studies to this discrete region of the brain. Our in vivo systemic LPS model shows many features associated with neurodegeneration, including increased cytokine production, increased synthesis of GDNF, NOS isoforms, and increased presence of immune cells within the olfactory bulb. These results imply that both circulating immune cells and cytokines are involved in endothelial signaling within the CNS and may, in turn, result in a compromised vascular barrier.

\section{Methods}

The protocol was approved by the University of Texas Animal Welfare Committee. The experiments were performed in adherence to the National Institute of Health Guidelines on the Use of Laboratory Animals. Male SpragueDawley rats $(300 \mathrm{~g})$ were treated with intravenous LPS in saline (LPS, $35 \mathrm{mg} / \mathrm{kg}$ ). Control animals were treated with vehicle (saline). Following LPS and/or saline administrations, animals were maintained for up to $48 \mathrm{~h}$ before euthanasia and removal of the brains.

\section{Brain sectioning and staining}

Brains were removed from control and LPS-treated animals at defined times after administration of LPS. The tissue was fixed, sectioned, and stained with hematoxylin and eo$\sin (\mathrm{H} \& \mathrm{E})$, or sectioned and probed with specific antibodies for fluorescence microscopy. Images of various sections were acquired, including the olfactory bulb, cortex, substantia nigra, and cerebellum, in stepwise sections (thickness 0.1$0.25 \mu \mathrm{m})$, following the guidelines of Paxinos and Watson (Paxinos and Watson 1997). Fluorescence intensity was quantified for labeled proteins, cytokines, and inflammatory cell markers as previously described (Bick and others 2008; Dinh and others 2009; Schiess and others 2010).

Tissue sections were probed with antibodies for the glial cell-derived neurotrophic factor (GDNF, sc-9010; Santa Cruz Biotech) and lysosomal-associated membrane protein (LAMP-1, sc-19992, Santa Cruz Biotech; CD107a, a marker for lymphocytic cells). To visualize specific immune systemassociated cells, sections were treated with a CD3 mouse monoclonal antibody (sc-20047, Santa Cruz Biotech; T cell marker) and recognizing mouse, human, and rat CD3.A CD20 antibody (Rabbit Polyclonal B-Cell marker, sc-15361; Santa Cruz; B-lymphocyte marker) was used as a marker for B cells. CD20 is a leukocyte surface antigen primarily expressed on B cells and we were unable to detect any costaining with the CD3 antibody. A CD44, a signaling molecule found on the surface of polymorphonuclear cells, was used as a marker for neutrophils (mouse monoclonal marker, sc9960; Santa Cruz Biotech). CD68 is found on the surface of macrophages and monocytes, (rabbit polyclonal sc-9139; Santa Cruz Biotech). Secondary fluorescent antibodies were purchased from Jackson ImmunoResearch. Tissue preparation and deconvolution fluorescence microscopy was as previously described (Poindexter and others 2002; Merritt and others 2007; Bick and others 2008).

Tissue sections were prepared and stained with H\&E using the standard techniques in the departmental Histology Services laboratory and as previously described for nerve tissues (www.uth.tmc.edu/pathology/research/histologylab/ technical.html) (Fix and others 1996).

\section{Circulating cytokine and nitric oxide level determinations}

Blood samples from LPS-treated and control animals were assayed for plasma cytokines using a commercial enzymelinked immunosorbent assay (ELISA) kit (R\&D Systems). Plasma NO levels were quantified by a modified chemiluminescence method of Radomski and others (1987) using a Sievers NO analyzer 270B (GE Analytical) (Doursout and 
others 2008). Nitrite concentrations were quantified by comparing measured signals to authentic sodium nitrate standards (20-400 pmol).

\section{Results}

A single intravenous injection of LPS elicited a systemic inflammatory response in conscious rats as indicated by the elevation of circulatory cytokines, IL-6, IL-1 $\beta$, and TNF- $\alpha$. A maximal increase was observed at approximately $3 \mathrm{~h}$ postinjection (Fig. 1A-C, respectively). Interestingly, TNF- $\alpha$ showed a biphasic response, with a secondary peak occurring at 24-48 h post-LPS exposure. Circulating levels of NO also showed a temporal increase (Fig. 1D) with a maximal response around $6 \mathrm{~h}$ postinjection.

Tissue from the olfactory bulb was sectioned and stained with H\&E to show the presence of immune-associated cells. Macrophages, neutrophils, and lymphocytes were identified throughout the LPS-treated brain tissue and cell types quantified by immunohistochemistry. Quantification of each of the immune cell types within the olfactory bulb demonstrated that the numbers of macrophages and neutrophils increased for up to $6 \mathrm{~h}$ post-treatment, and then rapidly decreased, while B cell and T cell numbers remained elevated for at least $12 \mathrm{~h}$ (Fig. 2A). LAMP-1, a marker for cytotoxic cells, which can include cytotoxic T cells, neutrophils, and macrophages, also showed an elevation in the olfactory bulb in a time-dependent manner (Fig. 2B). We further observed localizations of some of these inflammatory response cells with LAMP-1- and IL-6-positive cells often forming a cuff around blood vessels (Fig 3), lending credence to the involvement of the BBB as well as both central and peripheral immune cells having a role in neurodegeneration.

Measurement of individual cytokines within the olfactory bulb demonstrated an increase in TNF- $\alpha$, IL- $1 \beta$, IL- 6 , and IL10 (Fig. 4) with temporal changes very similar to those for the inflammatory cells within the olfactory bulb. As previously stated, NO production has been implicated in the progression of neurodegeneration (Hoang and others 2009). Using immunohistochemistry, we quantified the protein level of the iNOS isoform in the olfactory bulb and demonstrated dramatic and rapid increases in the tissue content of iNOS (Fig. 5). Increased levels of the neuroprotective GDNF in the olfactory bulb were observed on a similar time frame as the increased inflammatory response, suggesting an initiation of protective mechanisms (Fig. 6). However, in this current report, we are unable to determine whether this increase is due to an increase in the glial cell number, increased protein expression by glial cells, or increased uptake by neuronal cells.

Taken together, these data indicate that systemic administration of LPS stimulates an inflammatory response within the brain tissue closely resembling the response associated with the development of PD.

\section{Discussion}

While the precise cause(s) of neurodegenerative diseases is/are unknown, there is a consensus that an inflammatory event or episode is involved in the initiation of neurodegeneration (Arai and others 2006) and that chronic neuroinflammation, possibly resulting from an initial acute episode, is the sustaining and exacerbating route to a complete loss of neuronal signaling (Fiszer 2001; Frank-Cannon and others 2009). Further evidence that inflammation is at the center of the progression of neurodegeneration was reported by Rugbjerg and others (2009), who noted that there was a reduced risk of PD development in rheumatoid arthritis patients who had taken, or were taking anti-inflammatory medications. In a case report from 2003, a 22-year-old subject was accidentally exposed to LPS through an open wound. Subsequently, the subject developed neurodegenerative, Parkinson-like symptoms, including tremor and rigidity, and imaging a few years later showed significant damage to the
FIG. 1. Changes to circulating cytokines and reactive nitrogen species after a single systemic injection of lipopolysaccharide (LPS). Plasma levels of IL-6, IL-1 $\beta$, TNF- $\alpha$, and $\mathrm{NO}(\mathrm{A}, \mathbf{B}, \mathbf{C}$, and $\mathbf{D}$, respectively), were measured as described in Methods. Each value represents the mean of 12 independent experiments; error bars represent standard deviation (SD). *Significantly different from time $0, P \leq 0.01$.
A

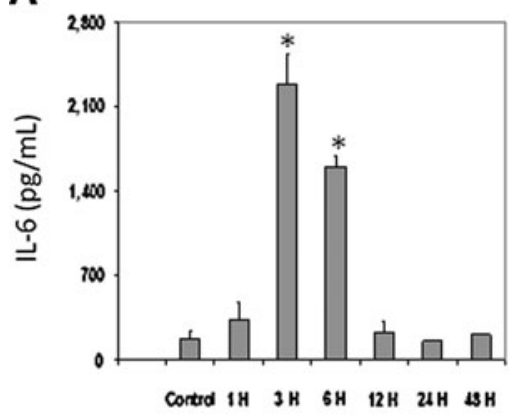

C

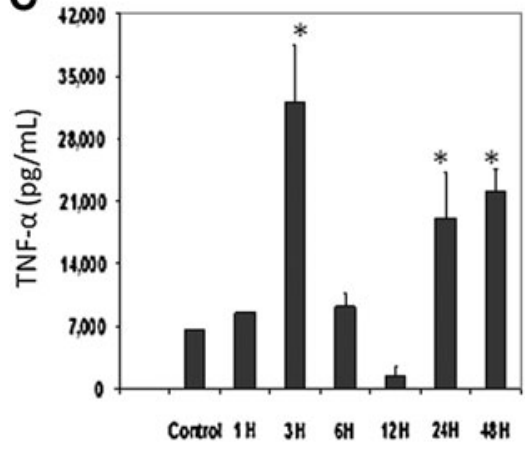

B

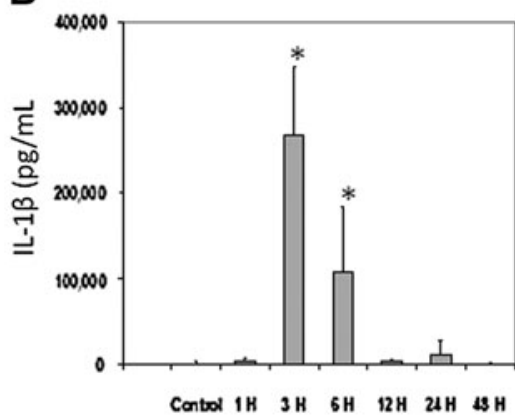

D

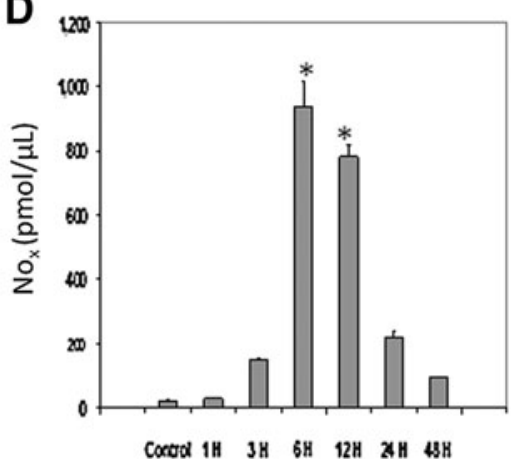


A

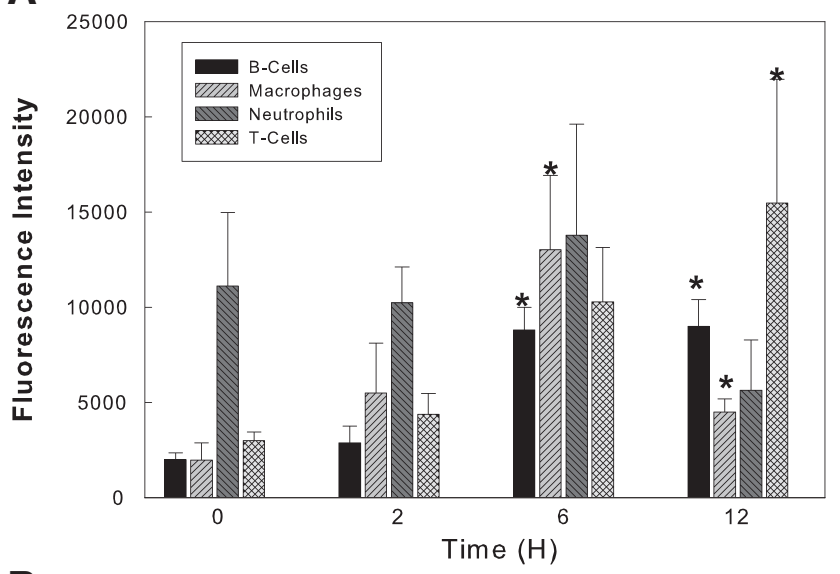

B

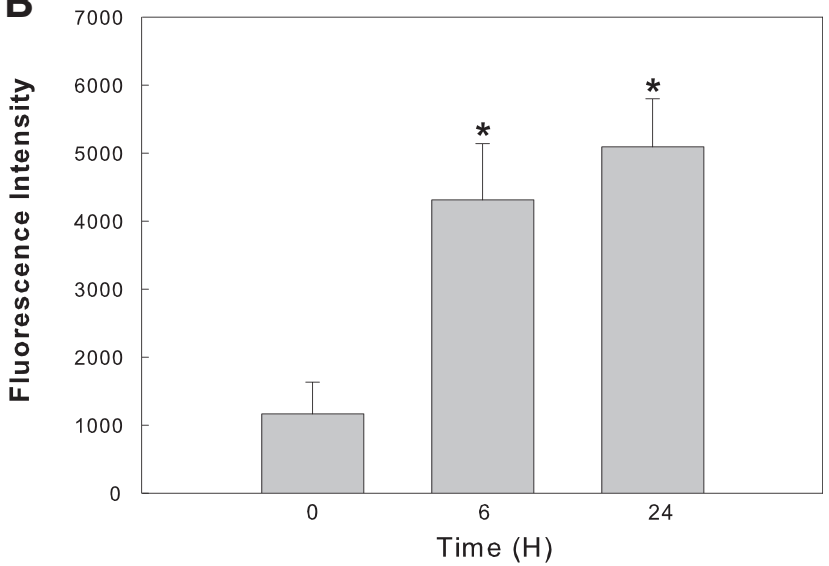

FIG. 2. Inflammatory cells in the olfactory lobe of animals treated with systemic LPS. B cells, macrophages, neutrophils, and $\mathrm{T}$ cells were individually quantified (A) by immunofluorescence. Cytotoxic cells were identified by lysosomal-associated membrane protein (LAMP)-1 positivity (B) and quantified by immunofluorescence as described in the Methods. Error bars represent SD $n=12$, *Values significantly different from time $0, P \leq 0.05$.

brain tissue (Niehaus and Lange 2003). It has also been suggested that an inflammatory reaction due to infection contributes to a neurodegenerative pathogenesis rendering inflammation a prime target for new treatment options (Arai and others 2006; Qian and others 2010).

Most of the studies of LPS administration in the brain are reported for cells in culture or by direct stereotaxic injection of LPS into the brain of rodents. Direct injection of LPS into the nigral area of rats induces the activation of microglia and loss of dopaminergic neurons (Herrera and others 2000). Intranigral injection of LPS into the brain has also been associated with increased levels of IL-1 $\beta$, TNF- $\alpha$, IL-6, and NO within the brain tissue (Arimoto and others 2007; Hernandez-Romero and others 2008) and changes in the locomotory activity by the animal (Hsieh and others 2002). Measurement of cytokine levels in cerebral spinal fluid from patients with defined neurodegenerative diseases, such as PD and Alzheimer's, is currently an area of intense interest for possible disease marker identification.

LPS activates the innate immune system by binding to the Toll 4 (TLR4) receptor principally on phagocytic cells. Systemic intraperitoneal or intravenous injection of LPS led to an increase in the expression of the TLR4 receptor on microglia (Chung and others 2010). CD14, a protein present in both soluble and membrane-bound forms, binds LPS and subsequently presents it to the TLR4 receptor for downstream pathway activation. Systemic injection of LPS leads to a robust increase in CD14 mRNA and transcription both within the microvasculature of the brain and in microglia throughout the parenchyma (Rivest 2003). Similar observations of CD14 expression were observed associated with Alzheimer's disease (Fassbender and others 2004). Recent reports from studies in mice indicate that brain uptake of circulating LPS, even after repeated injections, is extremely low $(0.025 \%)$ (Banks and Robinson 2010). Supporting other work concluded that LPS itself does not cross the BBB (Singh and Jiang 2004) even though many cell types in the CNS express TLR4 receptors (Chakravarty and Herkenham 2005). Systemic cytokines are able to cross this barrier (Banks and others 1995; Saija and others 1995). Recent evidence also supports the role of peripheral inflammation in the development of neurodegenerative diseases. Mild to moderate peripheral inflammation combined with intranigral injection of LPS increased the loss of dopaminergic neurons (Hernandez-Romero and others 2012) over that observed with the LPS alone.

In our studies, a single intravenous injection of LPS sufficient to stimulate an inflammatory response, but not sufficient to induce multiorgan failure elicited systemic increases in circulating inflammatory cytokines and NO. On a similar time scale, it also induced an increased expression of inflammatory cytokines within the brain tissue of the olfactory lobe. This was temporally closely related to increased levels of inflammatory cells, including cytotoxic cells, within this tissue. Some of these cells and cytokines were intimately associated with blood vessels within the tissue. It is likely that these cells extravasate through the endothelium into the perivascular space, and then into the parenchyma of the CNS. Once within the brain parenchyma, these inflammatory cells can release cytokines sufficient to activate the resident microglia. GDNF is produced by glial cells in many regions of the developing and adult brain. Production is stimulated as a potential defense against these inflammatory stimuli and damaged neurons can signal glial cells to upregulate GDNF production (Saavedra and others 2008). It is possible that regulation of the cross talk between neurons and glia may be mediated by cytokines. Although increased formation of iNOS within the olfactory lobe could be deemed an inflammatory response or a protective response, further work is necessary to determine its role. Our data indicate that in our experimental model, GDNF returns to baseline level, while levels of iNOS remain elevated for longer. It is important to note also that our observations relate to acute LPS exposure and, while it is tempting to extrapolate these into long-term models, without further research this is speculative. The role of other NOS isoforms within the microvasculature and parenchyma needs to be studied. Our data using immunofluorescence microscopy indicate changes in protein levels of our markers, whether this is due to an increase in the number of marker-positive cells or an increase in the expression level is actively being studied.

We hypothesized from our earlier work that exposure to circulating inflammatory cytokines, such as in a chronic viral infection or massive bacterial infection, will lead to a change in the cytokine and protein profiles within the brain. In such 
FIG. 3. Representative image of LAMP-1 (A) and IL-6 (B) fluorescence around an arteriole in the olfactory bulb of animals $12 \mathrm{~h}$ after treatment with a single systemic injection of LPS. C and D are representative images of the respective markers at the same time after injection of vehicle. Magnification: $\times 600$. A and $\mathbf{C}$ show smooth muscle actin (green), nuclei (blue), and LAMP-1 (white). B and D show smooth muscle actin (red), nuclei (blue), and IL-6 (yellow).
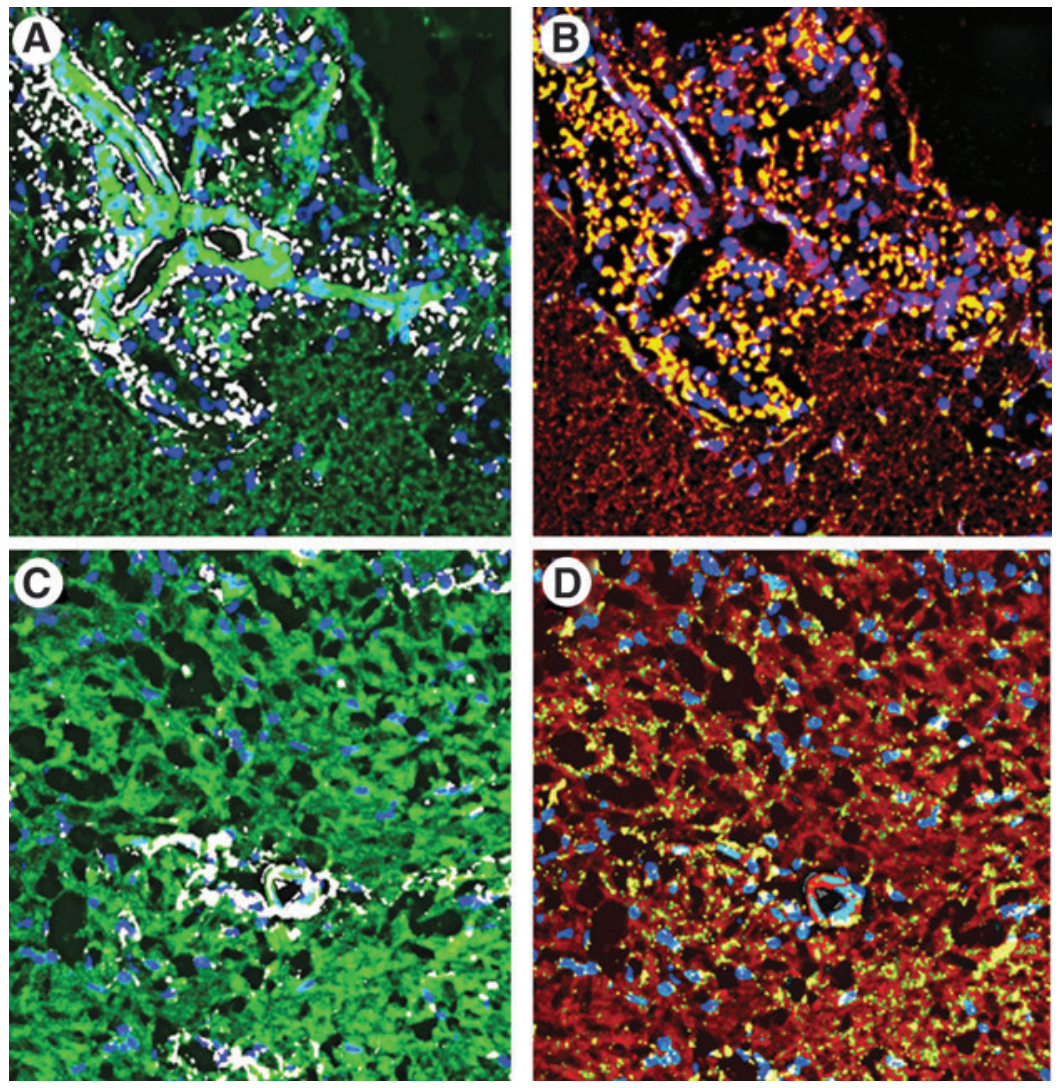

events, protective pathways could be insufficient to protect the functional neuronal cells. It is possible that certain cell types like the dopaminergic neurons are more sensitive to these changes and these cells would enter into neurodegenerative pathways. Misfolded proteins, colocalized cytokines, lymphocytes, NO, GDNF, NFKB, and many more factors are involved in neurodegeneration indicating that there is potentially a myriad of unknown mechanisms effective in the development of the associated diseases. Current consensus seems to be that this is an inflammation-based disease in

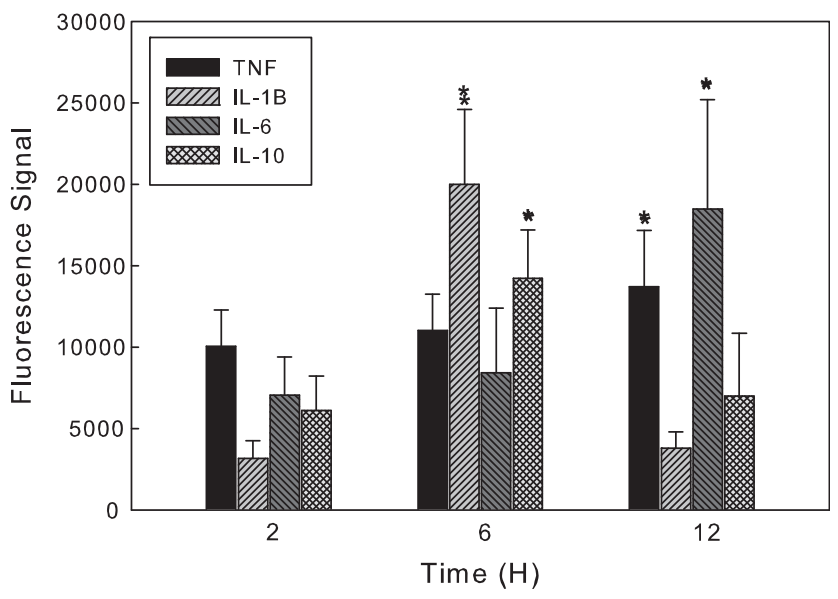

FIG. 4. Postexposure levels of inflammatory cytokines TNF- $\alpha$, IL-1 $\beta$, IL- 6 , and IL-10 in the olfactory lobe of animals given a single systemic injection of LPS. Error bars represent $\mathrm{SD}$ of at least 16 independent experiments. ${ }^{*}$ Values significantly different from time $0, P \leq 0.05$. which all causative factors are unknown (Chung and others 2010), possibly directing us to initiate anti-inflammatory therapy in patients who have had major inflammatory episodes (viral infection, bacterial infection, etc) as soon as they are capable of tolerating the medication (Chen and others 2003; Schiess and others 2003).

Neuroinflammation is an early problem of neurodegeneration and persists throughout the course of debilitating illness. Various factors, such as the vasoactive intestinal peptide and GDNF have been implicated in affording at least some neuroprotection (Dejda and others 2005; Tuncel and others 2005; Biju and others 2010). However, cells outside the

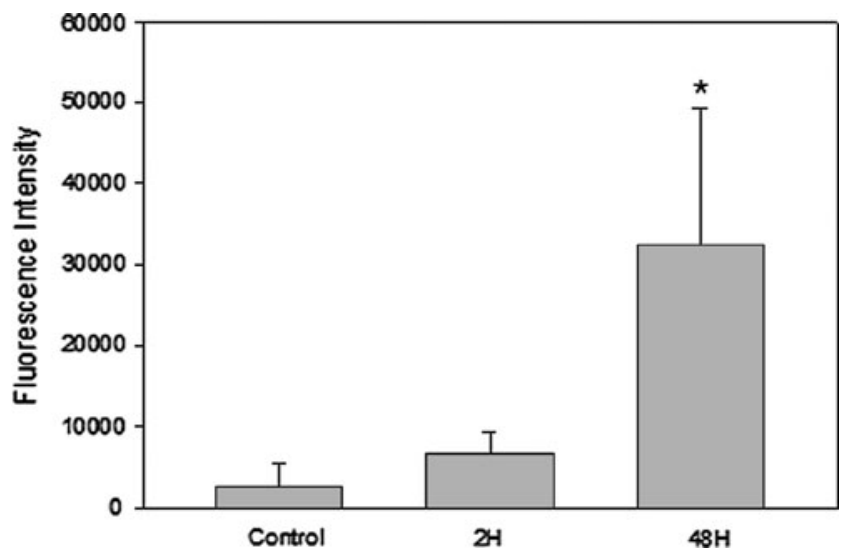

FIG. 5. Time dependence of the expression of iNOS in the olfactory bulb of rats given a single systemic injection of LPS. Error bars represent SD of at least 3 independent experiments. *Values significantly different from time $0, P \leq 0.05$. 

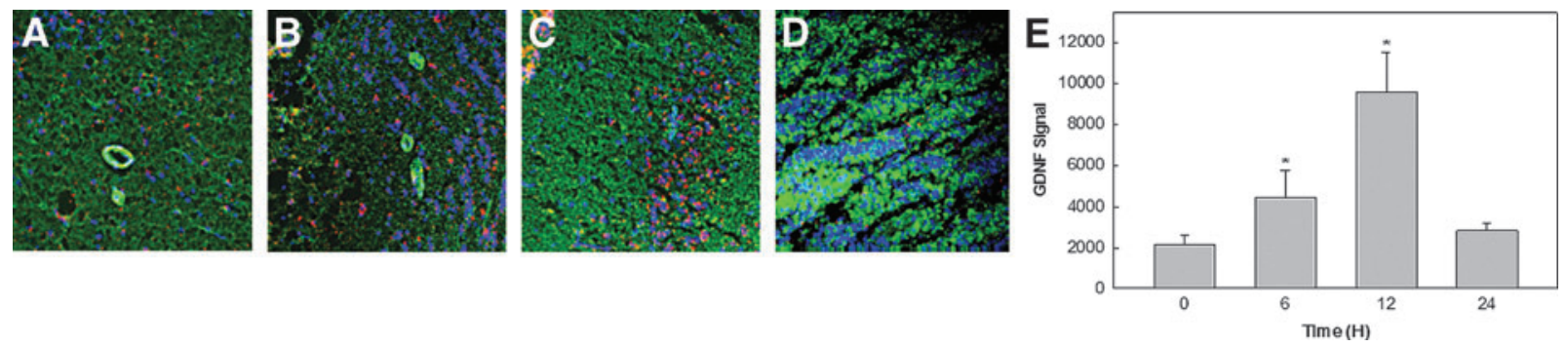

FIG. 6. Time dependence of glial cell line-derived neurotrophic factor (GDNF) expression in the olfactory bulb of rats after a single systemic injection of LPS. A, B, C, and D are representative images taken at $0,6,12$, and $24 \mathrm{~h}$ post LPS administration. Magnification $600 \times$; blue $=$ nuclei, red $=$ GDNF, green $=$ smooth muscle actin. E represents combined integrated data, $n=16$, error bars represent $\mathrm{SD} *$ Values significantly different from time $0, P \leq 0.05$.

CNS might have a role in the initiation and continuation of the pathologies (Theodore and others 2008). Studies reported herein support this hypothesis. Balances in cytokine production and the synthesis of protective neurotrophic factors might exist in a fine tuned balance that is chaotically altered in response to a severe inflammatory episode, or a subsequent inflammatory period affecting predisposed neurons. This balance remains a target for therapeutic challenges (Tuncel and others 2005; Smith and Cass 2007).

\section{Author Disclosure Statement}

No competing financial interests exist.

\section{References}

Arai H, Furuya T, Mizuno Y, Mochizuki H. 2006. Inflammation and infection in Parkinson's disease. Histol Histopathol 21:673-678.

Arimoto T, Choi DY, Lu X, Liu M, Nguyen XV, Zheng N, Stewart CA, Kim HC, Bing G. 2007. Interleukin-10 protects against inflammation-mediated degeneration of dopaminergic neurons in substantia nigra. Neurobiol Aging 28:894-906.

Banks WA, Kastin AJ, Broadwell RD. 1995. Passage of cytokines across the blood-brain barrier. Neuroimmunomodulation 2:241-248.

Banks WA, Robinson SM. 2010. Minimal penetration of lipopolysaccharide across the murine blood-brain barrier. Brain Behav Immun 24:102-109.

Bick RJ, Poindexter BJ, Kott MM, Liang YA, Dinh K, Kaur B, Bick DL, Doursout MF, Schiess MC. 2008. Cytokines disrupt intracellular patterns of Parkinson's disease-associated proteins alpha-synuclein, tau and ubiquitin in cultured glial cells. Brain Res 1217:203-212.

Biju K, Zhou Q, Li G, Imam SZ, Roberts JL, Morgan WW, Clark RA, Li S. 2010. Macrophage-mediated GDNF delivery protects against dopaminergic neurodegeneration: a therapeutic strategy for Parkinson's disease. Mol Ther 18:1536-1544.

Calopa M, Bas J, Callen A, Mestre M. 2010. Apoptosis of peripheral blood lymphocytes in Parkinson patients. Neurobiol Dis 38:1-7.

Carlson NG, Wieggel WA, Chen J, Bacchi A, Rogers SW, Gahring LC. 1999. Inflammatory cytokines IL-1 alpha, IL-1 beta, IL-6, and TNF-alpha impart neuroprotection to an excitotoxin through distinct pathways. J Immunol 163:3963-3968.

Chakravarty S, Herkenham M. 2005. Toll-like receptor 4 on nonhematopoietic cells sustains CNS inflammation during endotoxemia, independent of systemic cytokines. J Neurosci 25:1788-1796.
Chen H, Zhang SM, Hernan MA, Schwarzschild MA, Willett WC, Colditz GA, Speizer FE, Ascherio A. 2003. Nonsteroidal anti-inflammatory drugs and the risk of Parkinson disease. Arch Neurol 60:1059-1064.

Chiaretti A, Antonelli A, Mastrangelo A, Pezzotti P, Tortorolo L, Tosi F, Genovese O. 2008. Interleukin-6 and nerve growth factor upregulation correlates with improved outcome in children with severe traumatic brain injury. J Neurotrauma 25:225-234.

Chung DW, Yoo KY, Hwang IK, Kim DW, Chung JY, Lee CH, Choi JH, Choi SY, Youn HY, Lee IS, Won MH. 2010. Systemic administration of lipopolysaccharide induces cyclooxygenase-2 immunoreactivity in endothelium and increases microglia in the mouse hippocampus. Cell Mol Neurobiol 30:531-541.

Chung YC, Ko HW, Bok E, Park ES, Huh SH, Nam JH, Jin BK. 2010. The role of neuroinflammation on the pathogenesis of Parkinson's disease. BMB Rep 43:225-232.

Dejda A, Sokolowska P, Nowak JZ. 2005. Neuroprotective potential of three neuropeptides PACAP, VIP and PHI. Pharmacol Rep 57:307-320.

Dinh K, Poindexter BJ, Barnes JL, Schiess MC, Bick RJ. 2009. Fluorescence microscopy and $3 \mathrm{D}$ image reconstruction of cytokine initiated disruption of the Parkinson disease associated proteins alpha-synuclein, tau and ubiquitin in cultured glial cells. Cytokine 45:179-183.

Doty RL. 2011. Olfaction in Parkinson's disease and related disorders. Neurobiol Dis 46:527-552.

Doursout MF, Oguchi T, Fischer UM, Liang Y, Chelly B, Hartley CJ, Chelly JE. 2008. Distribution of NOS isoforms in a porcine endotoxin shock model. Shock 29:692-702.

Dutta G, Zhang P, Liu B. 2008. The lipopolysaccharide Parkinson's disease animal model: mechanistic studies and drug discovery. Fundam Clin Pharmacol 22:453-464.

Fassbender K, Walter S, Kuhl S, Landmann R, Ishii K, Bertsch T, Stalder AK, Muehlhauser F, Liu Y, Ulmer AJ, et al. 2004. The LPS receptor (CD14) links innate immunity with Alzheimer's disease. Faseb J 18:203-205.

Fiszer U. 2001. Does Parkinson's disease have an immunological basis? The evidence and its therapeutic implications. BioDrugs 15:351-355.

Fix AS, Ross JF, Stitzel SR, Switzer RC. 1996. Integrated evaluation of central nervous system lesions: stains for neurons, astrocytes, and microglia reveal the spatial and temporal features of MK-801-induced neuronal necrosis in the rat cerebral cortex. Toxicol Pathol 24:291-304.

Frank-Cannon TC, Alto LT, McAlpine FE, Tansey MG. 2009. Does neuroinflammation fan the flame in neurodegenerative diseases? Mol Neurodegener 4:47. 
German DC, Eagar T, Sonsalla PK. 2011. Parkinson's Disease: a role for the immune system year 2011. Curr Mol Pharmacol [Epub ahead of print] PMID: 21675953

Hernandez-Romero MC, Arguelles S, Villaran RF, de Pablos RM, Delgado-Cortes MJ, Santiago M, Herrera AJ, Cano J, Machado A. 2008. Simvastatin prevents the inflammatory process and the dopaminergic degeneration induced by the intranigral injection of lipopolysaccharide. J Neurochem 105:445-459.

Hernandez-Romero MC, Delgado-Cortes MJ, Sarmiento M, de Pablos RM, Espinosa-Oliva AM, Arguelles S, Bandez MJ, Villaran RF, Maurino R, Santiago M, et al. 2012. Peripheral inflammation increases the deleterious effect of CNS inflammation on the nigrostriatal dopaminergic system. Neurotoxicology 33:347-360.

Herrera AJ, Castano A, Venero JL, Cano J, Machado A. 2000. The single intranigral injection of LPS as a new model for studying the selective effects of inflammatory reactions on dopaminergic system. Neurobiol Dis 7:429-447.

Hirsch EC, Hunot S. 2009. Neuroinflammation in Parkinson's disease: a target for neuroprotection? Lancet Neurol 8:382-397.

Hisanaga K, Asagi M, Itoyama Y, Iwasaki Y. 2001. Increase in peripheral CD4 bright + CD8 dull + T cells in Parkinson disease. Arch Neurol 58:1580-1583.

Hoang T, Choi DK, Nagai M, Wu DC, Nagata T, Prou D, Wilson GL, Vila M, Jackson-Lewis V, Dawson VL, et al. 2009. Neuronal NOS and cyclooxygenase-2 contribute to DNA damage in a mouse model of Parkinson disease. Free Radic Biol Med 47:1049-1056.

Hsieh PF, Chia LG, Ni DR, Cheng LJ, Ho YP, Tzeng SF, Chang $\mathrm{MH}$, Hong JS. 2002. Behavior, neurochemistry and histology after intranigral lipopolysaccharide injection. Neuroreport 13:277-280.

Iravani MM, Sadeghian M, Leung CC, Jenner P, Rose S. 2012. Lipopolysaccharide-induced nigral inflammation leads to increased IL-1beta tissue content and expression of astrocytic glial cell line-derived neurotrophic factor. Neurosci Lett 510:138-142.

Levy OA, Malagelada C, Greene LA. 2009. Cell death pathways in Parkinson's disease: proximal triggers, distal effectors, and final steps. Apoptosis 14:478-500.

Long-Smith CM, Sullivan AM, Nolan YM. 2009. The influence of microglia on the pathogenesis of Parkinson's disease. Prog Neurobiol 89:277-287.

Merritt TM, Bick R, Poindexter BJ, Alcorn JL, Hecht JT. 2007. Unique matrix structure in the rough endoplasmic reticulum cisternae of pseudoachondroplasia chondrocytes. Am J Pathol 170:293-300.

Mogi M, Kondo T, Mizuno Y, Nagatsu T. 2007. p53 protein, interferon-gamma, and NF-kappaB levels are elevated in the parkinsonian brain. Neurosci Lett 414:94-97.

Monahan AJ, Warren M, Carvey PM. 2008. Neuroinflammation and peripheral immune infiltration in Parkinson's disease: an autoimmune hypothesis. Cell Transplant 17:363-372.

Munoz-Fernandez MA, Fresno M. 1998. The role of tumour necrosis factor, interleukin 6, interferon-gamma and inducible nitric oxide synthase in the development and pathology of the nervous system. Prog Neurobiol 56:307-340.

Niehaus I, Lange JH. 2003. Endotoxin: is it an environmental factor in the cause of Parkinson's disease? Occup Environ Med 60:378.

Paxinos G, Watson, C (Ed.). 1997. The Rat Brain in Stereotaxic Coordinates, 4 ed. New York (NY): Academic Press, Elsevier Inc.

Poindexter BJ, Pereira-Smith OM, Smith JR, Buja LM, Bick RJ. 2002. Dimensional reconstruction and localization of mortalin by deconvolution microscopy. Microsc Anal 16:21-23.
Qian L, Flood PM, Hong JS. 2010. Neuroinflammation is a key player in Parkinson's disease and a prime target for therapy. J Neural Transm 117:971-979.

Qin LW, Wu X, Block, ML, Liu Y, Breese GR, Hong JS, Knapp DJ, Crews FT. 2007. Systemic LPS causes chronic neuroinflammation and progressive neurodegeneration. Glia 55:453462.

Radomski MW, Palmer RM, Moncada S. 1987. Endogenous nitric oxide inhibits human platelet adhesion to vascular endothelium. Lancet 2:1057-1058.

Reale M, Iarlori C, Thomas A, Gambi D, Perfetti B, Di Nicola M, Onofrj M. 2009. Peripheral cytokines profile in Parkinson's disease. Brain Behav Immun 23:55-63.

Rentzos M, Nikolaou C, Andreadou E, Paraskevas GP, Rombos A, Zoga M, Tsoutsou A, Boufidou F, Kapaki E, Vassilopoulos D. 2009. Circulating interleukin-10 and interleukin-12 in Parkinson's disease. Acta Neurol Scand 119:332-337.

Reynolds AD, Banerjee R, Liu J, Gendelman HE, Mosley RL. 2007. Neuroprotective activities of CD4 +CD25 + regulatory $\mathrm{T}$ cells in an animal model of Parkinson's disease. J Leukoc Biol 82:1083-1094.

Rivest S. 2003. Molecular insights on the cerebral innate immune system. Brain Behav Immun 17:13-19.

Rugbjerg K, Friis S, Ritz B, Schernhammer ES, Korbo L, Olsen JH. 2009. Autoimmune disease and risk for Parkinson disease: a population-based case-control study. Neurology 73:14621468.

Saavedra A, Baltazar G, Duarte EP. 2008. Driving GDNF expression: the green and the red traffic lights. Prog Neurobiol 86:186-215.

Sachdeva R, Babbar R, Puri V, Agarwal S, Krishana B. 2011. Correlation between cognitive functions and nitric oxide levels in patients with dementia. Clin EEG Neurosci 42:190194.

Saija A, Princi P, Lanza M, Scalese M, Aramnejad E, De Sarro A. 1995. Systemic cytokine administration can affect blood-brain barrier permeability in the rat. Life Sci 56:775-784.

Scalzo P, Kummer A, Cardoso F, Teixeira AL. 2010. Serum levels of interleukin-6 are elevated in patients with Parkinson's disease and correlate with physical performance. Neurosci Lett 468:56-58.

Schiess M. 2003. Nonsteroidal anti-inflammatory drugs protect against Parkinson neurodegeneration: can an NSAID a day keep Parkinson disease away? Arch Neurol 60:1043-1044.

Schiess MC, Barnes JL, Ellmore TM, Poindexter BJ, Dinh K, Bick RJ. 2010. CSF from Parkinson disease patients differentially affects cultured microglia and astrocytes. BMC Neurosci 11:151.

Singh AK, Jiang Y. 2004. How does peripheral lipopolysaccharide induce gene expression in the brain of rats? Toxicology 201:197-207.

Smith MP, Cass WA. 2007. GDNF reduces oxidative stress in a 6hydroxydopamine model of Parkinson's disease. Neurosci Lett 412:259-263.

Stoll G, Jander S, Schroeter M. 2000. Cytokines in CNS disorders: neurotoxicity versus neuroprotection. J Neural Transm Suppl 59:81-89.

Theodore S, Cao S, McLean PJ, Standaert DG. 2008. Targeted overexpression of human alpha-synuclein triggers microglial activation and an adaptive immune response in a mouse model of Parkinson disease. J Neuropathol Exp Neurol 67: 1149-1158.

Tufecki KG, Genc S, Genc, K. 2011. The endotoxin-induced neuroinflammation model of Parkinson's Disease. Parkinson's Disease 2011:25. 
Tuncel N, Sener E, Cerit C, Karasu U, Gurer F, Sahinturk V, Baycu C, Ak D, Filiz Z. 2005. Brain mast cells and therapeutic potential of vasoactive intestinal peptide in a Parkinson's disease model in rats: brain microdialysis, behavior, and microscopy. Peptides 26:827-836.

Venkateshappa C, Harish G, Mythri RB, Mahadevan A, Bharath MM, Shankar SK. 2011. Increased oxidative damage and decreased antioxidant function in aging human substantia nigra compared to striatum: implications for Parkinson's disease. Neurochem Res 37:358-369.
Address correspondence to: Dr. Roger J. Bick

Department of Pathology University of Texas Medical School at Houston 6431 Fannin Street

Houston, TX 77030

E-mail: roger.j.bick@uth.tmc.edu

Received 7 August 2012/Accepted 30 December 2012 